\title{
Discovery of the Earliest Synthetic Carborundum (SiC) in Neolithic Jade Artifacts in Eastern China
}

\author{
Su-Jung Chou ${ }^{1}$, Jing-Guo Zhang ${ }^{2}$, Yun-Ao He ${ }^{3}$, Ying-San Liou ${ }^{4}$, Yang-Fang Chen ${ }^{5}$, Han-Yu Shih ${ }^{5}$, \\ James K. W. Lee ${ }^{6}$, George S. Burr ${ }^{1,7}$, Way-Fan Lien ${ }^{1}$, Mao-Hua Teng ${ }^{1}$, and Ching-Hua Lo ${ }^{1, *}$ \\ ${ }^{1}$ Department of Geosciences, National Taiwan University. Taipei, Taiwan \\ ${ }^{2}$ Institute of Cultural Relics and Archaeology of Anhui, Anhui, China \\ ${ }^{3}$ Institution of Cultural and Natural Heritage, Nanjing University, Jiangsu, China \\ ${ }^{4}$ Department of Natural Resources and Environmental Studies, National Donghwa University, Hualien, Taiwan \\ ${ }^{5}$ Department of Physics, National Taiwan University, Taipei, Taiwan \\ ${ }^{6}$ Department of Geological Sciences and Geological Engineering, Queen's University, Kingston ON, Canada \\ ${ }^{7}$ NSF-Arizona Accelerator Mass Spectrometer Laboratory, University of Arizona, Tucson AZ USA
}

Received 17 April 2013, revised 6 November 2013, accepted 21 February 2014

\begin{abstract}
Using Raman microscopy and scanning electron microscopy we have successfully identified, for the first time, synthetic silicon carbide (carborundum) particles in 15 unearthed relics and assorted remains from five out of six Neolithic sites ( 4000 - 7000 years b.p.) in Eastern China. Because of its extreme hardness, silicon carbide was apparently employed in the manufacture of ancient jade artifacts presumably as an abrasive for polishing. We show that Neolithic people may have already used this synthetic material to carve and polish both jade and quartz artifacts, contributing to the blooming development of the jade culture throughout ancient China.
\end{abstract}

Key words: Carborundum, Jade, China

Citation: Chou, S. J., J. G. Zhang, Y. A. He, Y. S. Liou, Y. F. Chen, H. Y. Shih, J. K. W. Lee, G. S. Burr, W. F. Lien, M. H. Teng, and C. H. Lo, 2014: Discovery of the earliest synthetic carborundum (SiC) in Neolithic jade artifacts in Eastern China. Terr. Atmos. Ocean. Sci., 25, 537-544, doi: 10.3319/ TAO.2014.02.21.01(TT)

\section{INTRODUCTION}

Jade has had a long and intimate connection with Chinese culture. The oldest known jade artifacts found in China are from Xinglongwa ( 7400 - 8200 years b.p.) in Inner Mongolia (Hu and Liu 1998). By the late Neolithic period ( 4000 years b.p.), jade had become a symbol of power and wealth, and by $\sim 2500$ years b.p., Confucius had endorsed the notion that jade's innate qualities were symbolic of the virtuous and moral aspects of humanity. Given both the early reverence for jade by Neolithic Chinese tribes and the later adoption of Confucianism, jade has become synonymous with Chinese culture, and has attracted much attention over the past few decades (Na 1980; Yang 1998; So and Douglas 1998; Douglas 2005).

Jade artifacts in China are usually made of nephrite which consists of felted intergrown microcrystalline

\footnotetext{
* Corresponding author

E-mail:loch@ntu.edu.tw
}

to cryptocrystalline tremolite-actinolite (Wen 1998). On Mohs hardness scale, nephrite and quartz are $6-7$ and 7 , respectively, so they are not easily carved or drilled. Nevertheless, the excavations of intricately carved nephrite and quartz artifacts suggest that the ancient Chinese must have possessed some sort of polishing abrasive material used in the production of such carvings as early as 8000 years b.p. (Zhang 2003; Lu et al. 2005). For example, vast numbers of intricately carved and polished jade and quartz artifacts have been found in the excavations of the Lingjiatan culture in Anhui and the Liangzhu culture in Jiangsu, Zhejiang and Shanghai; Neolthic sites dating from 4000 - 5300 years b.p. (Zhang 2003). Both jade and quartz artifacts dated to about 4000 years b.p., found at localities throughout China support the view that jade production and polishing technologies were widespread in the Neolithic (Na 1980; Yang 1998; Zhang 2003; Lu et al. 2005; Douglas and Yang 2008).

Several possible candidates for these elusive, polishing 
abrasive materials have been proposed in the literature. Suggestions range from the frequently found quartz tools and shark's teeth at archaeological sites, to corundum (Mohs hardness 9), and diamond (Mohs hardness 10) (Zhang 2003; Lu et al. 2005). However, no direct evidence has ever been found to which polishing abrasive material or materials were used. Although quartz tools could have been employed to roughly shape the artifacts, grinding powders would still be necessary to acquire the smooth polish that is characteristic of the jade artifacts. Shark's teeth (typically apatite in composition) are relatively soft and therefore an unlikely candidate (Zhang 2003; Lu et al. 2005). Although it has been suggested that ancient Chinese people may have used naturally occurring corundum or diamonds in the manufacture of jade artifacts (Zhang 2003; Lu et al. 2005), neither material has ever been found at Neolithic sites.

In "Chinese Jade Carving," Hansford (1950) describes the polishing abrasive materials in a jade workshop in Peking in 1939 (Anhui Provincial Institute of Cultural Relics and Archaeology 2009). A mixture of carborundum with loess, or calcareous sand called "pao yao" was used for the final polishing stage of jade artifacts. In spite of this observation, carborundum has never been found in association with ancient jades. Many studies show that carborundum can be produced by thermal processing of rice husks at temperatures $\sim 1150-1500^{\circ} \mathrm{C}$ and in the process the fine silicon particles in the plant material can be converted into silicon carbide by adding carbon from organic material (Hansford 1950; Adylov et al. 2003).

In this paper we describe the identification of minute carborundum particles in unearthed Neolithic relics and associated remains. The presence of abundant carborundum particles in many of the jade artifacts suggests that the development of the jade culture in ancient China may have been closely associated with the adoption of synthetic carborundum $(\mathrm{SiC})$ by tribes in Eastern China during the Neolithic period.

\section{SAMPLES AND ANALYTICAL METHODS}

The present study examines unearthed relics and other remains excavated from six Neolithic sites in Eastern China (Fig. 1). Four sites are in Jiangsu province: Yandun is a site of the Liangzhu culture, while the Dingshadi, Miaojishan and Chaoduntou sites predate the Liangzhu culture. Two sites are in Anhui Province, where Lingjiatan is a site of the Lingjiatan culture, Huangjiayan is a site of the Xuejiagang culture and they also predate the Liangzhu culture. The chronological and geographical relationships of these cultures, as suggested by previous studies (Tang 2002; Tian 2002; Yang 2002; Liethschmidt and Garbes 2002; He 2005a; Yan 2006; Yang 2009), are summarized in Table 1.

The 18 specimens collected from the abovementioned sites can be divided into five categories: (I) baked clay pieces containing wood-ash, in which some of the woodash may have reacted with clay to form $\mathrm{SiC}$ particles after baking; (II) pottery clay that may have been mixed with residual $\mathrm{SiC}$ particles; (III) residual sand-sized particles found inside pottery (possibly a storage container for the $\mathrm{SiC})$; (IV) particles that were carefully scraped off the surface of postulated jade-making tools; and $(\mathrm{V})$ particles that were carefully scraped from indentations within stone artifacts (Table 2 and Fig. 2). Note that the first two categories may represent the sources where the $\mathrm{SiC}$ was synthesized,

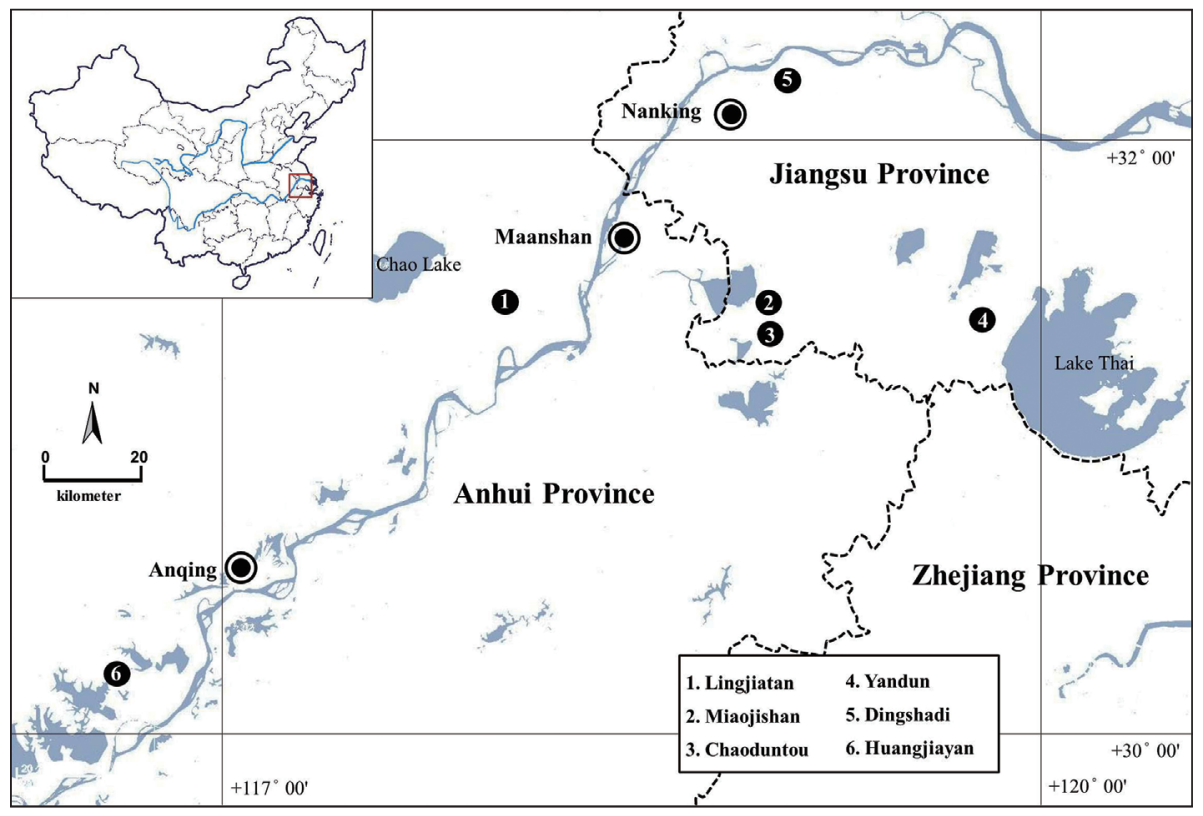

Fig. 1. Location map for the six Neolithic sites in Eastern China. 
Table 1. The stratigraphic table of Neolithic cultures in Eastern China.

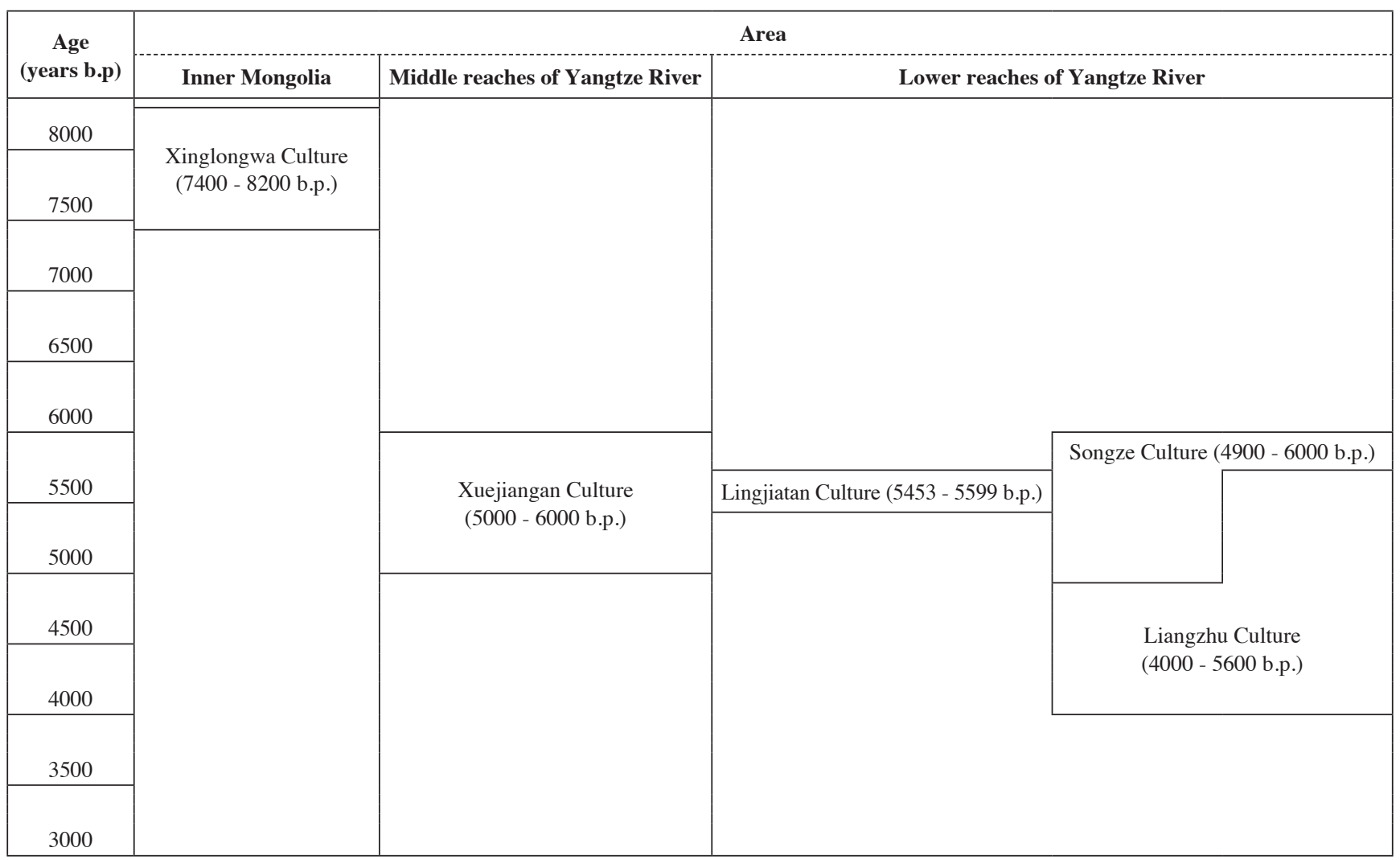

Table 2. 18 samples collected from the six Neolithic sites for the present study.

\begin{tabular}{|c|c|c|c|c|c|}
\hline Sample no. & Sample Description & Locality & Date (years b.p) & Category & $\mathrm{SiC}^{*}$ \\
\hline 1 & Baked clay samples containing wood-ash & \multirow{10}{*}{ Lingjiatan (Anhui Province) } & \multirow{10}{*}{ 5599 - 5453 (Lingjiatan Culture) } & I & O \\
\hline 2 & Red pottery paving piece & & & II & ○ \\
\hline 3 & Red pottery paving pieces & & & II & ○ \\
\hline 4 & Sands on the surface of jade axe & & & - & $\mathrm{X}$ \\
\hline 5 & Sands from a jade artifact & & & $\mathrm{V}$ & $\triangle$ \\
\hline 6 & Sands on the surface of stone artifact & & & $\mathrm{V}$ & $\triangle$ \\
\hline 7 & Sands on the surface of fine stone tool & & & IV & $\triangle$ \\
\hline 8 & Sands from holes in jade turtle & & & $\mathrm{V}$ & $\triangle$ \\
\hline 9 & Sands from holes in jade pipe & & & V & $\triangle$ \\
\hline 10 & Sands from holes in stone axe & & & V & $\triangle$ \\
\hline 11 & Sands from the surface of a jade artifact & Huangjiayan (Anhui Province) & 5000 - 600 (Xuejiagang Culture) & V & $\triangle$ \\
\hline 12 & Pottery piece & \multirow{2}{*}{ Yandun (Jiangsu Province) } & \multirow{2}{*}{$\sim 4000$ - 5600 (Liangzhu) } & II & $\triangle$ \\
\hline 13 & Sands from inside pottery & & & III & $\triangle$ \\
\hline 14 & Pottery piece & Dingshadi (Jiangsu Province) & $\sim 7622$ - 6955 (Neolithic Period) & II & $\bigcirc$ \\
\hline 15 & Sands from the surface of a drill & \multirow{2}{*}{ Miaojishan (Jiangsu Province) } & \multirow{4}{*}{ 〜900 - 6000 (Songze Culture) } & IV & $\triangle$ \\
\hline 16 & Sands from the surface of a drill & & & IV & $\triangle$ \\
\hline 17 & Sands from the surface of a drill & \multirow{2}{*}{ Chaoduntou (Jiangsu Province) } & & - & $\mathrm{X}$ \\
\hline 18 & Sands from the surface of a drill & & & - & $\mathrm{X}$ \\
\hline
\end{tabular}

Note: “O”: presence of highly pure $\mathrm{SiC} . " \triangle$ ”: presence of trace amount or poorly crystalline SiC. " $X$ ”, no trace of SiC. 
(a)

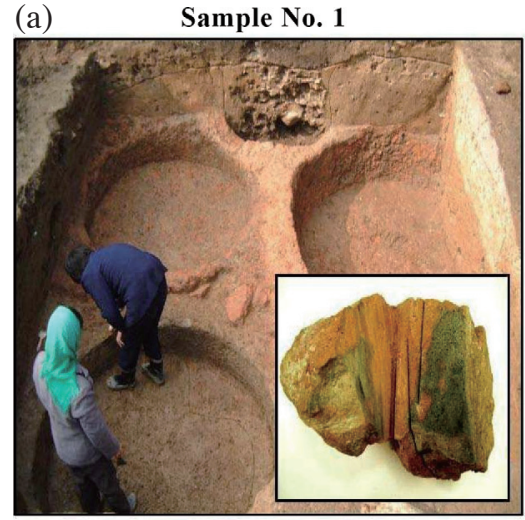

(c)

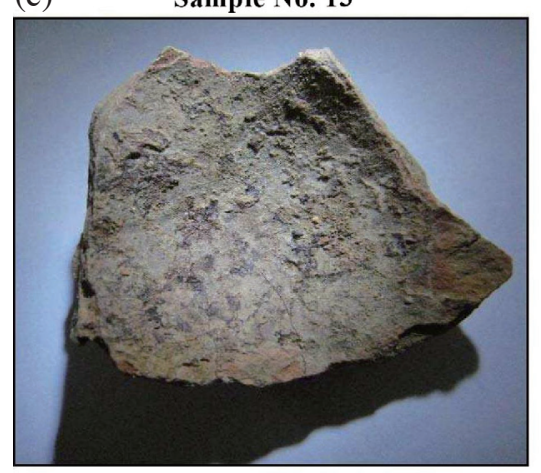

(e)

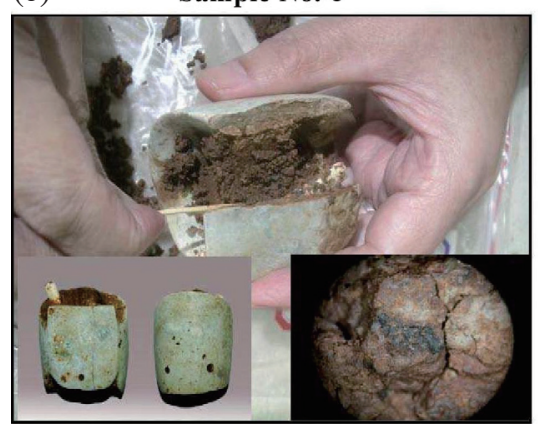

(b)

Sample No. 2, 3, 12, 14
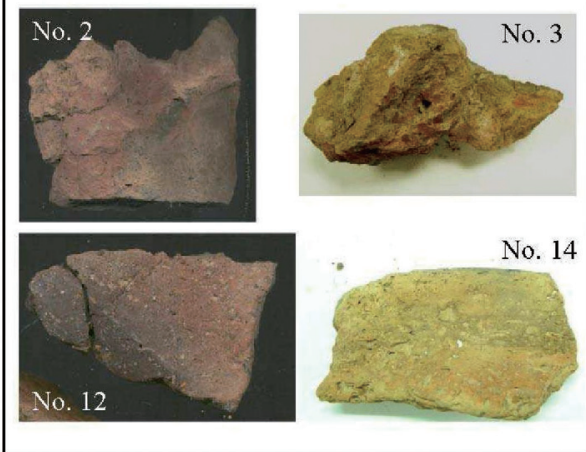

(d)

Sample No. 5

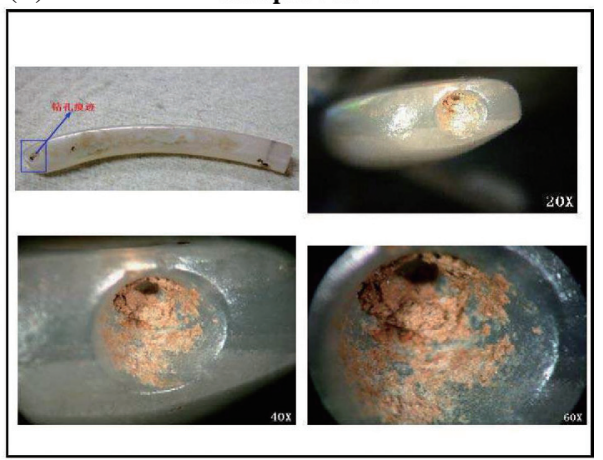

(f)

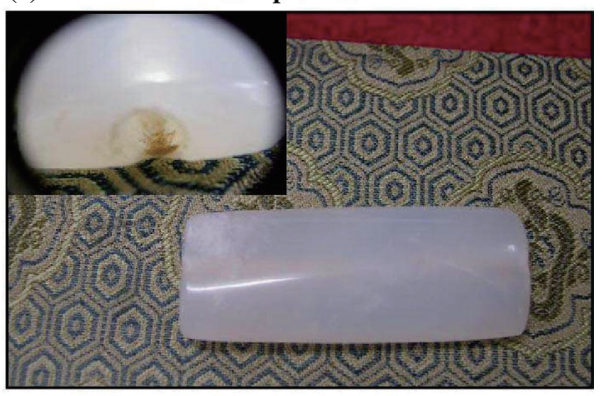

Fig. 2. Photography of representative samples: (a) Category I sample (No. 1) baked clay block contains wood-ash, collected from the Lingjiatan site; (b) Category II samples (Nos. 2, 3, 12, and 14) collected from red pottery paving pieces and pottery pieces; (c) Sample No. 13 (Category III) found inside the pottery; (d) Sample No. 5 (Category V) was scraped from the surface of jade artifacts collected from Lingjiatan; sand particle samples (Category V) were scraped from indentations on a jade turtle (Sample No. 8) (e); and a jade artifact (f), collected from the Lingjiatan site.

either intentionally or accidently. The third category may be from storage containers holding polishing abrasive powders for jade making. The last two categories are from excavated artifacts and any particles collected from the surface of the samples are likely to contain residual grinding materials. In addition, modern silicon carbide $(\mathrm{SiC})$ powder (Buehler, product no. 406418000080, grit 1000/P2000) has been examined for comparison.

Due to the small amount of $\mathrm{SiC}$ particles, it was impossible to use X-ray diffraction to determine the phases of the minerals in the samples. Raman spectroscopy and secondary electron microscopy (SEM) techniques were used in the present study. Micro-Raman spectroscopic analyses were carried out in two laboratories using a Jobin-Yvon T64000 Micro-Raman system at the Department of Physics, National Taiwan University, and a UV light LabRam HR800 Micro-Raman system at the Institute of Earth Sciences, National Dong Hua University. Chemical compositions and photomicrographs of the samples were obtained with a QUANTA 200 FEG SEM at the Department of Geosciences, National Taiwan University. The ${ }^{14} \mathrm{C}$ dating was conducted at the accelerator mass spectrometry (AMS) facilities at the University of Arizona and Lawrence Livermore National Laboratory. 


\section{RESULTS}

Early industrial synthesized carborundum is usually not pure due to its poor process control and contains a mixture of $\mathrm{SiC}$, quartz $\left(\mathrm{SiO}_{2}\right)$ and carbon (Shapiro et al. 1967; Jayaraman et al. 1987; Nakashima et al. 2003; Jin and Shi 2008; Yang 2009). As a result, Raman signal intensities vary depending on the different proportions of these components. If they are evenly mixed, the Raman show an A1 mode signal of $\mathrm{SiO}_{2}$ at $\sim 206 \mathrm{~cm}^{-1}, \mathrm{SiC}$ at $\sim 780$ and $\sim 970 \mathrm{~cm}^{-1}$, and $\mathrm{C}$ between $\sim 1000$ and $\sim 1800 \mathrm{~cm}^{-1}$ (Shapiro et al. 1967). The structure and size of the crystals also influence the position and strength of the Raman signals (Wieligor et al. 2005; Jin and Shi 2008).

Of the 18 samples from the six Neolithic sites studied, 15 samples contained $\mathrm{SiC}$ (Table 2). Four samples (Nos. 1 - 3 and 14) showed clear evidence of highly pure $\mathrm{SiC}$ fine crystal structure signals (Figs. 3a - d) similar to those found in modern industrial grade $\mathrm{SiC}$ (Fig. 3e). Among the remaining 14 samples, 11 showed mixed signals with varied and disordered SiC signals (Fig. 3f), reflecting poorly developed crystalline structures and size variation. Only three samples (Nos. 4, 17, and 18: one from Lingjiatan and two from Chaoduntou) showed no trace of SiC. Significantly,

(b)

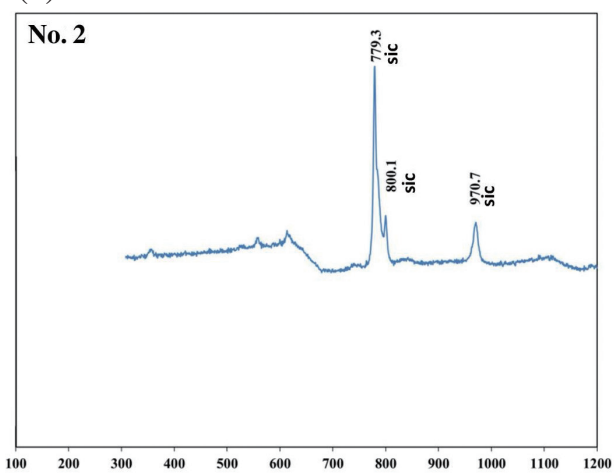

(d)
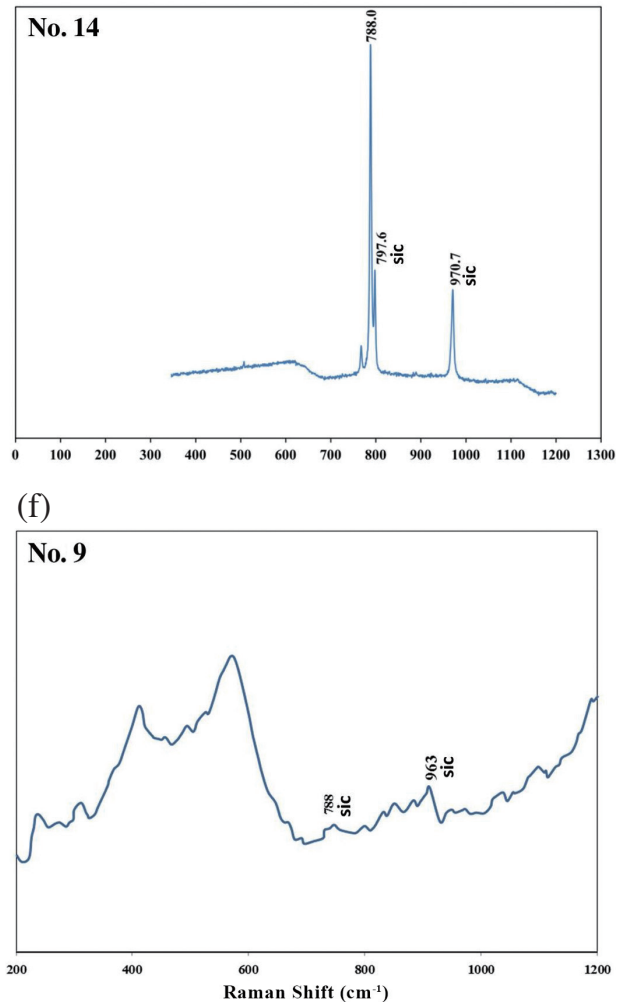

Fig. 3. Raman spectra for samples (a) No. 1 (baked clay block with wood-ash from Lingjiatan), (b) No. 2 and (c) No. 3 (red pottery paving pieces from Lingjiatan) and (d) No. 14 (red pottery paving piece from Dingshadi), which are all very similar to that of modern SiC (e), indicating the presence of pure $\mathrm{SiC}$ in baked clay and red pottery piece, whereas, that for the sand sample from the jade pipe (Sample No. 9) in the Lingjiatan site shows varied and disordered $\mathrm{SiC}$ signals (f). 
$\mathrm{SiC}$ was found in three samples of category IV (Nos. 7, 15, and 16) likely candidate for carving tools. Unlike modern industrial SiC particles (Fig. 4a), the SEM images show the surfaces and edges of the $\mathrm{SiC}$ particles are seriously weathered and cracked, with wear and corrosion marks (Fig. 4b); the particle sizes also vary greatly, between $28-80 \mu \mathrm{m}$. These characteristics suggest that the $\mathrm{SiC}$ particles may have been produced by an immature technological process with poor quality control.

Another eight carbon fragment samples were dated using the ${ }^{14} \mathrm{C}$ dating technique. The dating results are listed in Table 3. A carbon fragment in clay from Lingjiatan, Anhui yielded age of $\sim 5453$ - 5599 years b.p. Four samples of carbonized wood fragments, from Yandun of Yixing in Jiangsu at 4499 - 5054 years b.p., samples from Dingshadi, Jiangsu, yielded ages of 6955 - 7177 years b.p.

\section{DISCUSSION}

How did the ancient Chinese develop $\mathrm{SiC}$ as a polishing abrasive material? Moissanite is extremely rare as a naturally occurring mineral, so it is impossible to find and collect large quantities of moissanite in nature. However, carborundum may be produced naturally in common pottery-firing processes, when natural fuel, such as grass, wood or coal comes in contact with natural mineral quartz or sand. For example, sample No.1 clearly shows the co-existence of both $\mathrm{SiC}$ particles and wood-ash. Although the ancient processes were probably very crude and difficult to control, and the quality of the products was likely to be inconsistent, the process was easy to implement, even for the Neolithic tribes in Eastern China. In addition, eleven other samples of category I (not listed in Table 2) collected near sample No. 1 at Lingjiatan, all show the existence of $\mathrm{SiC}$ particles.

The discovery of this study, contrary to known history, pushes back the age of the first known synthetic SiC by several thousand years, to the Neolithic age. We may never know for sure whether the ancient people made $\mathrm{SiC}$ accidentally or on purpose. We do know, however, that Neolithic tribes in Dingshadi (now in Jiangsu Province) had successfully synthesized carborundum (sample No. 14) as early as 7622 years b.p. (Fig. 3d and Table 3). Furthermore, (a)

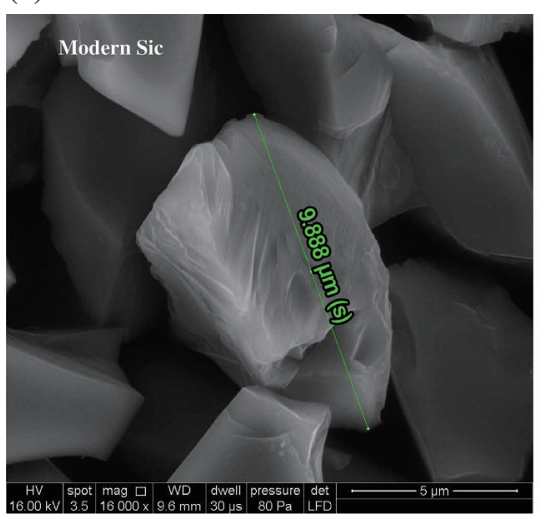

(b)

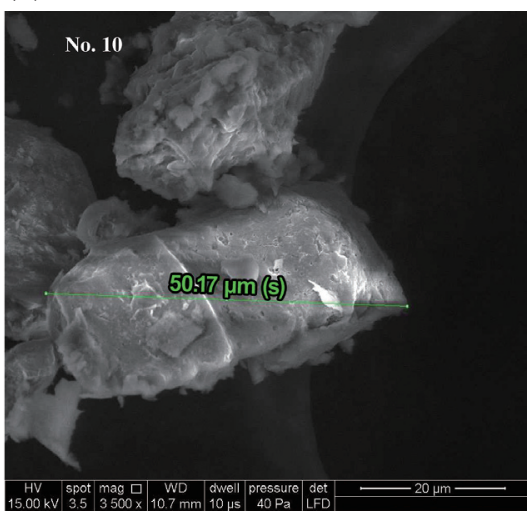

Fig. 4. SEM images for (a) a modern $\mathrm{SiC}$ particle from abrasive paper, showing a clean and sharp-edged $\mathrm{SiC}$ crystal grain of about $9.89 \mu \mathrm{m}$ in length, and (b) a SiC particle found in the hole of a stone axe at Lingjiatan (Sample No. 10); note that the surface and edges are severely weathered and cracked.

Table $3 .{ }^{14} \mathrm{C}$ dating results for 8 samples collected from three Neolithic sites in East China.

\begin{tabular}{ccccc}
\hline Samples & Location & Type of material & ${ }^{14}$ C age $(\mathbf{B P})$ & Likely date after dendrochronology \\
\hline NTY97-3 & Yandun site & Carbon fragment & $4089 \pm 39$ & $5000-4980$ \\
NTY97-4 & Yandun site & Carbon fragment & $4350 \pm 40$ & $4980-4840$ \\
NTY1-16 & Yandun site & Carbon fragment & $4400 \pm 35$ & $5054-4859$ \\
NTY2-4 & Yandun site & Carbon fragment & $4075 \pm 35$ & $4649-4499$ \\
HCT13 & Lingjiatan site & Ash in clay & $4780 \pm 45$ & $5453-5599$ \\
DSDY2a-1 & Dingshadi site & Carbon fragment & $6185 \pm 40$ & $7177-6955$ \\
DSDY2-14 & Dingshadi site & Carbon fragment & $6280 \pm 35$ & $7291-7157$ \\
DSDY2b-3 & Dingshadi site & Carbon fragment & $6670 \pm 60$ & $7622-7435$ \\
\hline
\end{tabular}


the existence of $\mathrm{SiC}$ is widespread, as evidenced from the unearthed relics in five out of the six Neolithic sites investigated (Table 2). The evidence from category IV and V SiC samples, which were collected directly from the surfaces or holes within tools or jade artifacts, suggests that the tribes in Lingjiatan had broadly adopted $\mathrm{SiC}$ for carving jade as early as $5453-5599$ years b.p. These groups are thus likely to be the first known humans to have employed synthesized polishing abrasive materials in the manufacture of jade artifacts. It is apparent that " $\mathrm{SiC}$ technology" also spread to the Liangzhu culture ( 5600 - 4000 years b.p.) (He 2005b), helping it to become the most prosperous and prolific jade cultural period in Neolithic times in China. Although there has never been a historical record about the kind of grinding materials used for jade processing, we suggest that the $\mathrm{SiC}$ technology could have had a profound influence on the subsequent development of jade culture in China.

As mentioned previously, the Dingshadi tribes of Eastern China manufactured carborundum as early as 7622 years b.p., although they did not seem to know how to use it in the production of jade artifacts. People in Lingjiatan in Anhui ( 5453 - 5599 years b.p.) likely improved on carborundum production while firing pottery, to produce greater amounts of carborundum for carving jade and other hard stones. Note that in order to carve and polish so many delicate jade artifacts, they would also have had to develop techniques to concentrate the minute amount of $\mathrm{SiC}$ particles spread throughout the pottery clay, although it remains unclear how this was accomplished. In a broader context, the results of this study may indicate the earliest use of synthetic abrasives in human history. At 5453 - 5599 years b.p., the Liangzhu culture adopted the technique, which they very likely inherited from the Lingjiatan culture. Under the Liangzhu culture, one of the most prosperous and prolific periods of jade production and culture in China's history, jade production bloomed and this development had a profound influence on the future development of jade culture in China. This study shows very strong evidence that the proliferation of jade culture in China likely had its roots in the serendipitous discovery of how to synthesize carborundum by Neolithic tribal peoples about 7622 years ago.

\section{CONCLUSIONS}

This study shows that synthetic silicon carbide (SiC) particles are common components of Neolithic potteries and occur on the surfaces of stone tools from Eastern China. SiC is extremely rare as a naturally occurring mineral, suggesting that its presence at five out of the six Neolithic sites could not simply be a coincidence. Its discovery may have been serendipitous during the firing of pottery, making it the first known manmade abrasive material. Because of SiC's extreme hardness (Mohs 9.5), it could be the elusive grinding and polishing abrasive material for which archeologists have been searching for many years. ${ }^{14} \mathrm{C}$ dating shows that $\mathrm{SiC}$ existed as early as $\sim 7622$ years b.p. at Dingshadi. Furthermore, the "SiC technology" was prevalent throughout the Lingjiatan culture ( 5453 - 5599 years b.p.) and appears to have been later passed on to the Liangzhu culture around 5300 years b.p. (Table 1), leading to the widespread development of jade carving in ancient China.

Acknowledgments This work was supported by grants from National Taiwan University and National Science Council, Taiwan. We would also like to acknowledge the technical support from the AMS laboratories at University of Arizona and Lawrence Livermore National Laboratory. The authors would also like to thank the two anonymous reviewers for their constructive comments.

\section{REFERENCES}

Adylov, G. T., Sh. A. Faiziev, M. S. Paizullakhanov, S. Mukhsimov, and É. Nodirmatov, 2003: Silicon carbide materials obtained from rice husk. Tech. Phys. Lett., 29, 221-223, doi: 10.1134/1.1565639. [Link]

Anhui Provincial Institute of Cultural Relics and Archaeology, 2009: New Discoveries in the Fifth Excavation of the Lingjiatan Site in Hanshan County, Anhui. Chin. Archaeol., 9, 63-73.

Douglas, J. G., 2005: A review of some recent research on early Chinese jades. Scientific Examination of Art: Modern Techniques in Conservation and Analysis, Proceedings of the National Academy of Sciences, The National Academies Press, Washington, DC, Vol. 254, 206-214.

Douglas, J. G. and J. Yang, 2008: Materials and technology of Chinese jades dating to the Western Zhou period (1050-771 BCE). Sci. China Ser. E, 51, 467-480, doi: 10.1007/s11431-008-0036-6. [Link]

Hansford, S. H., 1950: Chinese Jade Carving, London and Bradford, Lund Humphries Press, 145 pp.

He, G. J., 2005a: Jadeware raw material source of inquiry for Liangzhu Culture. Relics from South, 4, 28-30, doi: 10.3969/j.issn.1004-6275.2005.04.006. [Link]

He, Y. A., 2005b: Essay Collection of the Yangtze Culture, Vol. 3, Culture and History Press, China.

Hu, Y. and G. X. Liu, 1998: East Asian Jade: Symbol of Excellence, Vol. 1, Art Museum Chinese University of Hong Kong, Hong Kong, 131-133 pp.

Jayaraman, A., D. L. Wood, and R. G. Maines, 1987: Highpressure Raman study of the vibrational modes in $\mathrm{AlPO}_{4}$ and $\mathrm{SiO}_{2}$ ( $\alpha$-quartz). Phys. Rev. B Condens. Matter., 35, 8316-8321, doi: 10.1103/PhysRevB.35.8316. [Link]

Jin, B. and N. Shi, 2008: Analysis of microstructure of Silicon carbide fiber by Raman spectroscopy. J. Mater. Sci. Technol., 24, 261-264.

Liethschmidt, K. and J. Garbes, 2002: Silicon Carbide. 
Ullmann's Encyclopedia of Industrial Chemistry, Wiley-VCH, Weinheim.

Lu, P. J., N. Yao, J. F. So, G. E. Harlow, J. F. Lu, G. F. Wang, and P. M. Chaikin, 2005: The earliest use of corundum and diamond, in prehistoric China. Archaeometry, 47, 1-12, doi: 10.1111/j.1475-4754.2005.00184.x. [Link]

Na, T. L., 1980: Chronological Ancient Chinese Artifacts Survey, Wenwen Publishing House press, Taipei, 47$97 \mathrm{pp}$.

Nakashima, S., M. Higashihira, K. Maeda, and H. Tanaka, 2003: Raman scattering characterization of polytype in Silicon Carbide ceramics: Comparison with X-ray diffraction. J. Am. Ceram. Soc., 86, 823-829, doi: 10.1111/j.1151-2916.2003.tb03382.x. [Link]

Shapiro, S. M., D. C. O'Shea, and H. Z. Cummins, 1967: Raman scattering study of the Alpha-Beta phase transition in quartz. Phys. Rev. Lett., 19, 361-364, doi: 10.1103/PhysRevLett.19.361. [Link]

So, J. F. and J. G. Douglas, 1998: East Asian Jades: Symbol of Excellence, Vol. 1, Chinese University of Hong Kong press, Hong Kong, 148-163. (in Chinese)

Tang,J.P., 2002: Brief report on the sixth season of excavation on Xuejiagang site, Anhui Province. Jianghan Archaeol., 2, 3-13, doi: 10.3969/j.issn.1001-0327.2002.02.001. (in Chinese) [Link $]$
Tian, M., 2002: Discussion on Neolithic Jades from Southwest of Anhui Province. Jianghan Archaeol., 1, 58-66, doi: 10.3969/j.issn.1001-0327.2002.01.006. (in Chinese) [Link]

Wen, G., 1998: East Asian Jades: Symbol of Excellence, Vol. 2, Chinese University of Hong Kong press, Hong Kong, 217-221. (in Chinese)

Wieligor, M., Y. Wang, and T. W. Zerda, 2005: Raman spectra of silicon carbide small particles and nanowires. J. Phys. Condens. Mat., 17, 2387-2395, doi: 10.1088/0953-8984/17/15/010. [Link]

Yan, W. M., 2006: Lingjiatan, Cultural Relics Press, Beijing, 1-3. (in Chinese)

Yang, B. D., 1998: History of Ancient Jade Articles, Forbidden City Press, Beijing, 17-54. (in Chinese)

Yang, B. D., 2009: On the source of Ancient Jade in China. Cultural Relics of Central China, Vol. 2, 54-58. (in Chinese)

Yang, N., 2002: Liangzhu Culture and Chinese civilization. Cultural Relics of Central China, Vol. 2, 11-13. (in Chinese)

Zhang, J. G., 2003: Comparison of slight markings on Jade Artifacts found at Lingjiatan and Fuquanshan of the Liangzhu Culture. Zhejiang Acad. J., 125-132. (in Chinese) 